\title{
DE LA CONSIDERACIÓN FILOSÓFICA DEL SUFRIMIENTO A LA GESTIÓN DE LOS RECURSOS HUMANOS EN LAS EMPRESAS
}

\author{
EDUARDO GISMERA TIERNO \\ JOSÉ LUIS FERNÁNDEZ FERNÁNDEZ \\ JESÚS LABRADOR FERNÁNDEZ \\ Universidad Pontificia Comillas
}

\begin{abstract}
RESUMEN: Desde los albores de la existencia humana, el sufrimiento, como constante antropológica, se ha constituido en una de las preocupaciones fundamentales de los hombres. Se le ha prestado atención constante, pero ello no ha de ser óbice para que no sigamos haciéndolo. La Filosofía puede contribuir a aportar luz a este concepto en nuestros días, en tanto en cuanto el problema del sufrimiento, a pesar de haber recibido respuestas muy distintas en las distintas épocas del pensar humano, parece persistir. Con el presente artículo buscamos aproximarnos al concepto del sufrimiento desde la luz que aportan algunos de los paradigmas filosóficos relevantes, al objeto de identificar algunas aplicaciones prácticas que favorezcan una gestión de recursos humanos más adecuada, tanto desde un punto de vista ético, como desde el lado de la rentabilidad empresarial. Ofrecemos por tanto propuestas para una gestión de recursos humanos responsable, sostenible y eficiente, de la mano del pensamiento filosófico.
\end{abstract}

PALABRAS CLAVE: sufrimiento en las empresas; gestión de personas; recursos humanos; sufrimiento y filosofía.

\section{Philosophical consideration of suffering and human resources management in companies}

ABSTRACT: Since the dawn of human existence, suffering, as an anthropological constant, has become one of the fundamental concerns of men. Continuous attention has been paid to it, which, however, should not suppose an obstacle for us to continue doing so. Philosophy can contribute to shed light on this concept in our days, insofar as the problem of suffering, despite having received very different responses at different times of human thinking, seems to persist. The present work seeks to approach the concept of suffering from the light provided by some of the most relevant philosophical paradigms, in order to identify some practical applications in order to facilitate more adequate human resource management, both from an ethical point of view and from the business profitability side. We therefore offer proposals for responsible, sustainable and efficient human resource management, hand in hand with philosophical thought.

KEY WORDS: suffering in companies; people management; human resources; suffering and philosophy.

\section{INTRODUCCIÓN: OBJETO Y MÉTODO}

En tanto en cuanto el ser humano participa de la actividad empresarial, ésta se impregna inevitablemente de características humanas. El principal signo distintivo de los humanos es el de la experiencia emotiva, además de la racional. Ninguna 
emoción es por tanto ajena a su actividad profesional. Tampoco el sufrimiento, como consecuencia. La experiencia de uno de los autores de este trabajo como directivo de recursos humanos, y su experiencia de sufrimiento propio y ajeno en el entorno empresarial, servirán de asidero del que partimos. Así, surge la intención de estudiar en profundidad la experiencia de sufrimiento de las personas en las organizaciones empresariales actuales y tratar de fortalecer su abordaje de la mano del pensamiento filosófico.

La Filosofía constituye una dimensión de la cultura desde tiempo inmemorial y por tanto, no puede ser ajena al problema del dolor y el sufrimiento de los seres humanos. Para unos, el sufrimiento proviene de la ignorancia de la realidad o de uno mismo; para otros tiene su origen en las malas obras humanas, o en una manifestación fatalista del destino y consustancial a la esencia misma del hombre; hay épocas en las que se considera que el apego y el deseo sin límite por lo perecedero causa sufrimiento en tanto en cuanto aparta al hombre de la naturaleza que lo conforma; para otros es la separación del comportamiento moral basado en la experiencia y la intuición a partes iguales lo que hace padecer a los hombres (López Sáenz, 2010).

La liberación producida en Occidente se ha traducido en un consumismo sin freno en el que todo se mide desde un punto de vista cuantitativo, en torno al principio del rendimiento y la rentabilidad como únicos parámetros válidos. Olvidamos en nuestra época sin embargo que el denominado nivel de vida ha de incluir otros factores cualitativos como la gratitud por cuanto poseemos, la liberación del sentimiento global de culpa o la supresión de algunos miedos infundados de antaño (López Sáenz, 2010)

Resulta también característico de nuestros días el acercamiento del pensamiento y la cultura de Oriente y Occidente. Es lo que Milton Santos denomina la globalización perversa (Seligmann-Silva, 2014), una suerte de riada en la que la pobreza global se incrementa, en la que el empleo es cada vez más precario, en la que la clase media ya no posee la calidad de vida por la que se caracterizaba. El desamparo se homogeniza, se hacen uniformes la lacras en toda la humanidad y lo hacen de forma pareja en Oriente y Occidente.

El modelo económico actual, más allá de sesgos ideológicos cada vez de menor calado, se basa en la objetivación, la planificación y la utilización de los recursos, objetivos a los que se subordina la vida del ser humano (Levinas, 1991). La existencia de la tecnología, la industria, la objetivación de cuanto acontece, la manipulación de los individuos en torno al trabajo y a la posesión de cosas materiales, conforman el estado de las cosas y se constituyen en el ámbito de poder predominante (Sánchez Meca, 2010).

En ese contexto, la situación individual y en la mayoría de las ocasiones anónima, de sufrimiento, no se produce en un ámbito cerrado y hermético, sino en el seno de la vida en grupo a la que todos los seres humanos nos vemos abocados. Por tanto, el mayor o menor grado de sufrimiento se verá influído por nuestra situación en dicho grupo y será mayor o menor en función de la situación de poder o de subordinación en que se encuentre cada uno (Georges, 2002). El sufrimiento tiene un componente inespecífico muy amplio, de modo que las circunstancias y la experiencia previa de cada individuo pueden influir en que el impacto de una situación adversa en una persona sea mayor o menor. 
La lógica preocupación por la rentabilidad de las empresas no tiene en cuenta que, para mejorarla, es necesario considerar el número de personas que dicen sufrir en ellas. La mejora del bienestar de las personas, tanto de las que se encuentran en su seno, como del resto de la sociedad, puede y debe ser un fin en sí mismo, y además garantía de una mayor rentabilidad (Pinto de Almeida \& Da Costa Leao, 2012). La forma actual de considerar a los seres humanos como recursos en las organizaciones ha producido como consecuencia un incremento del sufrimiento en los puestos de trabajo y por tanto una disminución en la eficacia de la pretendida rentabilidad (Baudelot \& Michael, 2011). Se podría suponer, por tanto, que muchos de los métodos actuales de trabajo, ponen en riesgo la salud mental, psíquica y social de un elevado número de personas.

Describe la situación actual Byung-chul Han, del siguiente modo: «Vivimos una fase histórica especial, en la que la libertad misma da lugar a coacciones. La libertad del poder hacer genera incluso más coacciones que el disciplinario deber. El deber tiene un límite. El poder hacer, por el contrario, no tiene ninguno. Es por ello por lo que la coacción que proviene del poder hacer es ilimitada. Nos encontramos, por tanto, en una situación paradójica. La libertad es la contrafigura de la coacción. La libertad, que ha de ser lo contrario de la coacción, genera coacciones. Enfermedades como la depresión y el síndrome de burnout son la expresión de una crisis profunda de la libertad. Son un signo patológico de que hoy la libertad se convierte, por diferentes vías, en coacción» (Han, 2014).

Se trata de un asunto en absoluto sencillo que debe hacernos reflexionar en aras de comprender juntos los procesos que tienen lugar y que deben ser entendidos para poder transformar las causas que ocasionan padecimiento en las personas. Es además un desafío, sin duda, de carácter ético, que puede y debe contribuir a la mejora de la salud de la sociedad, todo ello con la intención de recuperar la vitalidad de las personas que se ven afectadas por situaciones de desgaste mental y que ocasionan sufrimiento (Seligmann-Silva, 2014).

En las organizaciones actuales, los trabajadores han de cumplir unos exigentes objetivos de empresa siguiendo normas preestablecidas, a la vez que se les exigen grandes niveles de autonomía y responsabilidad para ser capaces de dar respuesta a situaciones novedosas, inesperadas, para identificar la aparición de problemas y darles respuesta sin perjudicar el cumplimiento de los citados objetivos de empresa (Han, 2014). Esta forma de trabajo bajo presión se ocasiona por la gran cantidad de órdenes de toda índole que recibe el trabajador a la vez que se mantiene una alta exigencia de excelencia en el resultado. A este factor hay que añadir que la llegada de las nuevas tecnologías facilita las tareas, pero requiere una mayor vigilancia, exige estar alerta también en períodos que están fuera del horario laboral (Boltanski \& Chiapello, 2002).

Así las cosas, las empresas, en las que hoy pasamos gran parte de nuestro tiempo, deberían esforzarse por descubrir, y analizar en su caso, algunos efectos nocivos que nacen de su modo de organizarse y que pueden afectar a las personas de forma directa. Esto es así por razones económicas, pero también éticas; por mera responsabilidad social, y en aras de cumplir con su misión más intrínseca. Nuestro objetivo no es otro que, a modo de cala, podamos sugerir si las empresas de hoy, y a partir de la reflexión filosófica, pudieren tratar de prevenir, descubrir y/o paliar el sufrimiento, caso de existir, en las organizaciones de nuestros días. 
El presente trabajo tiene como punto de referencia fundamental una importante limitación teórica y práctica de la disciplina de Recursos Humanos —o de Gestión de Personas- en las organizaciones. A la par, se trata de ver cómo se puede tratar de cubrir la citada carencia a partir de la interpretación del sufrimiento humano en las concepciones básicas de la historia del pensamiento filosófico.

El objeto que se persigue es ofrecer a las organizaciones empresariales actuales el bagaje interpretativo de las concepciones básicas de la Historia de la Filosofía respecto al sufrimiento. Este fin se concreta en los siguientes aspectos:

1.- Facilitar un análisis de la interpretación del sufrimiento en las concepciones básicas de la Filosofía a fin de que pueda ser utilizado por las áreas de gestión de personas de las organizaciones actuales.

2.- Delimitar el concepto de sufrimiento en las organizaciones.

3.- Ofrecer a los responsables de gestión de personas de las organizaciones, herramientas de conocimiento del sufrimiento y de cómo lo afrontaron etapas básicas del pensamiento filosófico.

El trabajo de investigación contendrá por tanto:

a.- Una contribución conceptual sobre la noción de malestar organizativo y sufrimiento en las organizaciones, enriquecido éste por la visión de la Filosofía.

b.- Una contribución también conceptual complementaria de modelos de gestión de personas actuales con vistas a sugerir la inclusión de la prevención, detección y/o gestión del sufrimiento.

Para alcanzar el objetivo descrito, se ha empleado una metodología cualitativa basada en el análisis documental, de una parte, y en la experiencia social de los propios investigadores de este trabajo.

Así, desde un punto de vista epistemológico, siguiendo la clasificación de Burrell y Morgan (1979), nos hemos posicionado en todo caso en una perspectiva hermenéutica, habida cuenta de nuestra intención de analizar un mundo social siempre complejo. A partir de un paradigma interpretativo, cualitativo, tratamos de entender la realidad, conscientes de que no seremos capaces de reducir la cuestión a fórmulas matemáticas comprobables tal y como propugna el método cuantitativo. Debemos por tanto referir a la importancia para nuestro estudio de la contextualización frente a la abstracción (Carretero, 2006).

Tratamos de reflejar la situación en que se encuentra la gestión de recursos humanos en las empresas actuales en lo que hace al sufrimiento, bajo el paraguas de la interpretación filosófica como palanca de mejora de la situación.

\section{El sufrimiento en las concepciones básicas de la Historia de la Filosofía}

\subsection{Una aproximación al concepto}

El sufrimiento constituye uno de los grandes temores de la humanidad, motivo por el que cualquier cultura ha intentado encontrarle un sentido con el objetivo principal de evitarlo o, en su caso, de disminuir sus efectos. Ya Sófocles en el siglo 
V antes de Cristo dijo que la tragedia humana más trascendente es su imposibilidad para evitar el dolor. Es cierto que el dolor presenta múltiples caras en función de las más diversas circunstancias, pero no lo es menos que en todas ellas produce sufrimiento.

El mundo en que vivimos, globalizado, sugiere encontrar una definición de sufrimiento que pueda ser transcultural, si bien lo inespecífico del concepto lo convierte en una tarea muy compleja. La mayoría de los autores que han tratado de definir el sufrimiento abogan por la complementariedad de éste con el término «dolor» (Montoya Juárez, Schimidt Río-Valle, \& Prados Peña, 2006), si bien aceptan por regla general la definición que propuso en el año 1982 Eric Cassell y que dice que se trata de «un estado de severo estrés asociado con eventos amenazantes para la integridad de la persona» (Cassell, 1982). Afirma además que el sufrimiento de las personas está condicionado por la sociedad y la cultura de cada momento y lugar.

Algunos autores afirman que «el sufrimiento es un estado de dolor más o menos permanente experimentado por el sujeto en el seno de una sociedad y cultura concreta, al enfrentar una amenaza percibida como capaz de destruir su propia integridad física o psicosocial, y ante la cual se siente vulnerable e indefenso» (Montoya Juárez, Schimidt Río-Valle, \& Prados Peña, 2006).

Se ha discutido antaño, si bien hoy se hace en menor medida, si el sufrimiento proviene de forma exclusiva del daño físico, o si también la psique tiene algo que decir. Hoy por hoy es doctrina asentada que el dolor puede provenir por razones de daño físico, o por razones psicológicas que también producen sufrimiento a las personas (Denault, Lussier, Mongeau, Paille, et al., 2004). Existe en ese sentido un componente del concepto de sufrimiento que ha de tenerse en cuenta para justificar su subjetividad, y es la sensación del individuo de la propia vulnerabilidad. Dicho de otro modo, todo sujeto que se siente vulnerable sufre en mayor o menor medida (Black \& Rubinstein, 2004).

Los profesionales experimentan momentos de presión en los que, el mero riesgo sobre la pérdida del trabajo, su sola posibilidad, les hace sentirse en extremo vulnerables debido a las responsabilidades que asumimos en la sociedad actual y que nos condicionan en menor o mayor medida. Ante esta situación, unas personas se defienden mediante la exteriorización de una posición de endurecimiento personal; otros padecen sin embargo sufrimiento emocional que la sociedad juzga como signo de la citada vulnerabilidad. En cualquiera de las opciones, el ser humano percibe el trabajo que deberá realizar por el resto de su vida profesional como una ardua y costosa tarea, un callejón sin salida en el que siempre estará acompañado por una forma de sufrimiento (Morse, 2000). Esta percepción está claramente influida por el contexto ideológico y por las estructuras de las organizaciones de nuestros días.

No es por lo tanto únicamente la experiencia de dolor físico lo que provoca el sufrimiento, sino que hemos de tener en cuenta, tanto más en el mundo empresarial, la percepción subjetiva que hace que el sufrimiento sea mayor o menor en circunstancias similares. Así, podemos afirmar que el sufrimiento puede ser físico, pero también psicológico; puede tener su origen en la sinrazón de acciones humanas y también ante lo que no comprendemos y nos aboca a la muerte física de forma inevitable.

Nótese que nos referimos aquí al sufrimiento como esa parte que es evitable, que podríamos paliar, o eliminar antes incluso de su aparición, teniendo en 
cuenta que existe, además, una parte de dolor en el mundo, inabarcable para nosotros. Aristóteles se refirió a este último en su Metafísica al asumir que en el mundo existe el orden y la belleza, del mismo modo que existe el desorden y la fealdad (Aristóteles, 1998). Su conocimiento y las causas de su aparición deberían acercanos a la concepción de Erasmo del ser humano como un ser nacido para la paz y la concordia, confiados en que junto a aquellos que nos rodean podremos encontrar el necesario reposo (Erasmo, 2007).

El problema del sufrimiento ha recibido respuestas muy distintas de la Filosofía, y en múltiples ocasiones incluso opuestas. Unos lo explican desde la racionalidad del mundo y otros adoptando una perspectiva irracional. En realidad, el sufrimiento es algo universal que, eso sí, conoce distintas actitudes para afrontarlo en períodos diferentes de la historia. La aproximación al estudio racional del sufrimiento, y su conceptualización, no ha sido homogénea, ni mucho menos, en la Historia de la Filosofía y que incluso ha llegado a propuestas contradictorias en uno u otro tiempo (González García, 2010).

Han sido en ocasiones los mismos filósofos quienes han desdeñado su posible misión de ayuda a una colectividad que sufre. Incluso han llegado a afirmar que el pensador ha de mantenerse intencionadamente apartado de hacer o proponer aplicaciones prácticas a su labor, a riesgo de acabar con la integridad moral que a su juicio se deben a ellos mismos y a sus lectores y estudiosos (Peirce, 1898).

Pero hay otro grupo de pensadores que abogan, de forma decidida, por tratar de responder qué puede hacer la Filosofía por el hombre y afirman que ésta no puede renunciar a comprender lo que ocurre en el mundo en que se encuentra porque esa es la razón misma de su existencia. La reflexión filosófica en tanto que se pregunta por el ser y su existencia, ha tratado a lo largo de la historia con la experiencia del dolor (Cantillo, 2010). Afirman que el saber especulativo, entre el que se encuentra la Filosofía, debe procurar el consuelo, el alivio a los destinatarios de su misión, ya sea de forma individual, ya colectivamente (Morera de Guijarro, 2010).

En tanto en cuanto nos interesa para captar la gestión de personas en el ámbito organizativo, sugerimos tratar de comprender lo más granado del pensamiento filosófico y, a modo de cala, como ya va dicho, proponer una interpretación posible del sufrimiento en nuestros días, desde la reflexión en torno a cuatro grandes momentos del pensar humano: Antiguo Oriente, Grecia y Roma, Cristianismo e Islam, para poder así, provisionalmente, aplicarlo a un mundo global, cambiante y doliente como el que vivimos, en buena medida, en el ámbito profesional.

\subsection{Doctrina no-dual en el Antiguo Oriente}

En algunas épocas del pensamiento humano, el sufrimiento ha constituido el asunto central del proceso reflexivo. Tal ha sido así en el Lejano Oriente, China y Japón. El máximo interés de todas las enseñanzas, desde épocas antiquísimas hasta nuestros días es precisamente la liberación del sufrimiento allá donde se presente. El pensamiento oriental tiene asimismo una misión eminentemente práctica, una función liberadora del ser. La fuente del sufrimiento es la ignorancia de la realidad; no tanto una ignorancia de conocimiento, como de carácter existencial. Sin embargo, cuando se adquiere el verdadero conocimiento, la oscuridad da paso a la luz y cesa el dolor (Cavallé Cruz, 2010). Hoy pasamos mucho tiempo en las 
empresas, lo que las convierte en lugares susceptibles de albergar dolor, motivo por el que nos interesa conocer esta doctrina.

El pensamiento oriental afirma que la realidad es «no-dual». Este término alude a una única realidad, pero que es diferente de la unidad tal como la comprenden algunos monismos desarrollados en Occidente. Podemos hablar de una única substancia que no queda delimitada en nada ni respecto a algo distinto de sí, pero no de unidad (Vigne, 1995). Encontramos la doctrina no-dual en el Vedanta Advaita, en el shivaismo, en el budismo, en el taoísmo, en el sufismo, en la gnosis shiita, y también en parte de la filosofía griega (orfismo, platonismo y neoplatonismo), en ciertas variantes místicas, en el hermetismo y en la kabala hebrea (Cavallé Cruz, 2010). Todas estas son formas de pensamiento que comparten la concepción del ser humano y la realidad en distintas épocas y zonas geográficas como un todo, única substancia indivisible

Una de las tradiciones orientales más características a este respecto es la denominada como decimos Vedanta Advaita Índico, o Vedanta de la no dualidad. El Vedanta Advaita no puede considerarse una doctrina religiosa, ni apela a la fe, pero tampoco a la razón. Afirma que el sufrimiento nace de la ignorancia, entendida ésta como un conocimiento erróneo o inexacto de la naturaleza, el yo y la realidad. Se trata sencillamente de un camino basado en la experiencia de los seres humanos que, transformados, alcanzan la lucidez que conduce a la alegría, a la libertad interior y a la erradicación del sufrimiento. El ser humano es intrínsecamente el mismo en Oriente y en Occidente, motivo por el que las enseñanzas del Vedanta Advaita son igualmente válidas para cualquier época y cualquier situación (Cavallé Cruz, 2010). Según esta doctrina, el sufrimiento en las empresas actuales se produciría por desconocimiento de la realidad en la que habita el trabajador. La falta de información, de formación, o de un horizonte claro, podrían así se motivo de sufrimiento.

Afirma el pensamiento oriental que el origen de todo sufrimiento es la creencia de las personas en que son seres que existen de forma separada del Universo, de que son seres diferenciados del todo que constituye cuanto existe. Se trata de una sensación de no perfección, de no dominarlo todo, de poder ser algo, pero no poder ser lo otro, lo que produce dolor (Merlo, 1994). Cuando nos identificamos con lo que tiene límites, con los límites de nuestro propio ser, sentimos dolor. El dolor es una sensación que se produce cuando sentimos que podemos perder algo, y cuando ansiamos ganar todo cuanto creemos que no poseemos (Nisargadatta, 2000). El mundo individualista de nuestros días promueve la competencia entre unos y otros y, como consecuencia, una situación de separación contraria a la Unidad de todo cuanto existe. La sensación de soledad lo es también de temor constante a la pérdida del puesto de trabajo, o de la posibilidad de tener cuanto no poseemos y querríamos poseer.

El ego tiene en cuenta, a cada instante, el tiempo psicológico, suscita en la persona tomar recuerdos y experiencias del pasado y los proyecta en el futuro. La realidad para la doctrina no-dual se sustenta en el ya, en el ahora. No existe nada más que el tiempo presente. En todo caso, cualquier reflexión sobre el pasado o sobre el futuro, sólo puede estar teniendo lugar ahora, en el momento presente (Shankaracharya, 1965).

La idea de "yo», y de «lo mío», son las que provocan todo conflicto interno, y son ideas que provienen de un conocimiento desviado, falso, del Ser. La liberación 
de la aflicción se produce cuando se alcanza el autoconocimiento, que uno no se encuentra separado del resto de personas, y que se halla como parte de una globalidad que lo une todo (Nisargadatta, 2000). Esta enseñanza sería de gran utilidad en las empresas, que tendrían que complementar sus modelos de gestión de personas para sustituir el individualismo reinante por una comunidad de trabajadores real y solidaria.

En otro orden de cosas, el pensamiento oriental distingue entre los términos «dolor»y «sufrimiento». Afirma que el dolor, como opuesto al placer, forma parte inevitable de toda existencia. El sufrimiento, sin embargo, en tanto en cuanto evitable, se produce como consecuencia de una lucha interna e inútil por evitar el dolor y buscar el placer. El enfrentamiento con los hechos que acontecen es lo que produce el sufrimiento, por causa de resistirnos a lo que sucede y a pretender otra cosa (Cavallé Cruz, 2010).

Sugiere esta reflexión que cierto conformismo vital, dejar ir y venir los acontecimientos y entenderlos en el seno de un conocimiento diferente de la integridad del Ser, producirá como resultado la desaparición del sufrimiento, independientemente de que en ocasiones sintamos placer, y en otras sintamos dolor. La mente del hombre consciente de su identidad es como un reflejo que todo lo capta, pero nada le afecta (Zhuangzi, 1972). Recuerda esta forma de pensamiento al estoicismo, movimiento filosófico fundado por Zenón de Citio en el año 301 a.C. y que, con autores como Marco Aurelio, Séneca, Epícteto o Cicerón, extiende su predominio hasta bien entrado el siglo II de nuestra era y que ha vuelto a emerger en momentos y autores de gran relevancia, incluido Adam Smith, padre de la Economía moderna (Boeri, 2004).

Para los estoicos, que influirán como veremos más adelante en los primeros padres de la Iglesia, pero también en Descartes y Kant, no son los hechos los que nos hacen sufrir, sino la interpretación que hacemos de los mismos. El estoicismo considera a la persona como parte de una gran familia universal y a la naturaleza humana como medida para evaluar normas y leyes (Hirschberger, 1968). La interpretación de los distintos roles de los empleados en las organizaciones, el afán de lucha desmedida de algunos empleados serán causa de sufrimiento para ellos y para el entorno según el pensamiento filosófico que analizamos. Es la supresión del deseo lo que equilibra nuestro lugar en el mundo y lo que produce la ausencia de sufrimiento (Nisargadatta, 2000).

\subsection{El sufrimiento en la antigüedad clásica}

«En Grecia se asiste a la germinación del filosofar con una pureza y radicalidad superiores a cuanto ha venido después. El tema capital de la historia de la filosofía griega consiste en averiguar por qué el hombre, al llegar a cierto nivel de su historia, se vio obligado a ejercitar un menester rigurosamente nuevo y desconocido que hoy llamamos filosofar» (Marías, 1941).

El autoconocimiento que propugna el pensamiento en Oriente como vía al cese del sufrimiento, da paso al conocimiento per sé, a la sabiduría, como bálsamo del padecimiento de los seres humanos en la antigua Grecia. Debemos aclarar no obstante que el concepto clásico de sabiduría se refiere a quien es capaz de aunar el dominio sobre lo teórico y sobre lo práctico, a la combinación de intelecto y ciencia 
como vía para alcanzar el conocimiento perfecto, como escribiera Aristóteles en su Ética a Nicómaco (Aristóteles, 2010).

Nietsche denominó a esta actitud «talento para el sufrimiento» en el sentido de que la preparación del hombre produce una mejor aceptación del sufrimiento, hasta el punto de otorgarle tratamiento de ingenuidad, componente que cree consustancial a las tragedias griegas (Nietzsche, 1886). La condición de sabio, además, evita que las personas culpen «a los dioses» de los males que les acaecen. Zeus, en la Odisea, afirma: «¡Desde luego, cómo culpan los mortales a los dioses! afirmando que de nosotros proceden todos los males. Pero son ellos mismos los que se procuran con sus desatinos dolores en exceso» (Homero, 2007). Invita esta forma de pensar a fortalecer los planes de formación de las empresas, pero no solo en cuanto a su capacidad para transmitir conocimientos, sino que también debe procurar convertir en hombres sabios a los trabajadores. La sabiduría, más allá del mero aprendizaje de conceptos, evitaría sufrimiento en las empresas.

No debe cegarnos en el caso griego la importancia de sus descubrimientos, ni todo cuanto avanzó el ser humano durante su preponderancia en el mundo. A este dato, sin duda incuestionable, debemos añadir que durante varios siglos, el pueblo griego carece por completo de esperanza (Marías, 1941). Se viven momentos ciertamente difíciles, de modo que los habitantes helenos creen que el dolor es inevitable en la vida, manifestación que se escenifica en la tragedia griega, máximo exponente del citado vivir desesperado (Morera de Guijarro, 2010). Las crisis económicas de nuestros días, la carencia de horizontes de algunos trabajadores, pueden aprender de Grecia y de cómo abordaron el problema del sufrimiento y la desesperanza.

En la filosofía griega, sobretodo en Platón y Aristóteles, se manifiesta que existe una relación directa entre la experiencia de sufrimiento de las personas y la verdad. Dicho de otra forma, la autenticidad es responsable directa de la felicidad en las personas, y en sentido contrario, el engaño produce indefectiblemente dolor. Platón, además, relaciona la ausencia de sufrimiento y la verdad con la idea de Bien que se encuentra más allá de toda sustancia y constituye la esencia misma del Ser. Aristóteles abunda en este pensamiento y deduce que obrar bien y vivir bien han de ser sinónimos de ser feliz, de no sufrir en todo caso (Marías, 1941). Convendría que los modelos de gestión de personas estableciesen protocolos en torno a la verdad. El comportamiento ético de los distintos departamentos debe fomentar el rigor y la certitud de su misión. El establecimento de la mentira entre compañeros produce sufrimiento en las personas como vemos.

Hasta la llegada de Alejandro Magno, el saber griego se concentraba básicamente en Atenas; desde luego de forma exclusiva en territorio griego. Sin embargo, las sucesivas conquistas provocaron la llegada de otros pueblos y el lógico choque cultural entre ellos. Así las cosas, los filósofos se creen compelidos a proponer los valores capaces de hacer posible la convivencia tras la llegada de otros pueblos, también poseedores de sus propias creencias y valores (Copleston, 1901). Es común también hoy la fusión y/o adquisición de empresas y la unión de trabajadores con diferentes culturas y modos de hacer. Nos interesa por eso la experiencia griega y cuanto podamos aprender de ella. Dos fueron las principales corrientes de pensamiento que, como parte de su propuesta, y a lo que nos concierne, trataron de interpretar el sufrimiento humano: estoicos y epicúreos. 
Para los estoicos, ya citados con anterioridad, la naturaleza predispone a los seres humanos a obrar con virtud, pero éstos, a pesar de su concepción determinista del Universo por la que la senda de cada uno está previamente descrita, mantienen la libertad necesaria para inclinarse por elegir una forma viciosa de vida, aún a sabiendas de que esta actitud les producirá dolor.

Los estoicos consideran que las acciones no son buenas o malas en sí mismas, sino que se convierten en buenas a malas en función de la intención con la que se realicen. Reconocen asimismo que para que exista el bien es necesario que exista también el mal, y para obrar con virtud debe existir el vicio. Desde el punto de vista ético, y con gran influencia de Séneca, siquiera en un período tardío, su pensamiento nos recuerda mucho al Cristianismo ya que afirmaban que las personas debían amar por igual a todos los habitantes del mundo, del mismo modo que se amaban a sí mismas.

Para los epicúreos, tan avanzados para la época que a su escuela podían entrar mujeres y esclavos, es el placer lo que produce la ausencia de sufrimiento, y por tanto la felicidad. Sin embargo, debe entenderse que la concepción de placer para los epicúreos no es sinónima del hedonismo, y venía enmarcado entre los límites de la lógica prudencia.

Desde un punto de vista ético, el epicureismo propone elegir los placeres de forma que pensemos las consecuencias que pueden conllevar en el futuro. Si un placer actual podría producir un mayor sufrimiento a posteriori, aquel debiera ser evitado. Sin embargo, apuestan por afrontar un padecimiento presente, si del mismo se puede suponer un mayor placer futuro.

Afirman los epicúreos, y consideramos este punto muy importante, que para alcanzar la ausencia de sufrimiento, es importante alcanzar lo que ellos denominan la ataraxia, que no es otra cosa que la vida sin preocupaciones. Para ellos, el sufrimiento moral era peor que el padecimiento físico. La ataraxia-apátheia es entendida como la tranquilidad de ánimo, reposo y equilibrio y se considera la meta que toda vida ha de alcanzar (Séneca, 2009). Vivimos hoy en un mundo en el que predominan las preocupaciones de toda índole, incluidas las profesionales. Tener trabajo es un privilegio en lugar de un derecho. La inseguridad de los puestos de trabajo hace muy difícil que el mundo laboral de hoy pueda fomentar una mayor tranquilidad en los empleados aunque, como vemos, debieran hacerlo.

\subsection{Interpretación del dolor en el cristianismo}

El cristianismo trae consigo una forma distinta de pensamiento desconocida hasta su llegada; marcando un importante hito en el pensamiento occidental. Esto es así porque el punto de partida de la reflexión de los cristianos es distinta de la existente hasta ese momento debido a que aparece el concepto de "Creación», desconocido hasta entonces y nuevo punto de partida del quehacer filosófico (Marías, 1941).

Sin embargo, como toda cultura, también el Cristianismo constata que el sufrimiento en el mundo es un hecho incontestable y presente en toda existencia, motivo por el que trata de encontrársele una explicación. El concepto de dolor en los primeros momentos de existencia del cristianismo, se encuentra asociado al concepto de pecado (Escobar Gómez, 2010). Los primeros cristianos aceptaron, del mismo modo que lo había hecho el budismo, un carácter místico del sufrimiento 
y adoptaron una actitud de aceptación ante el mismo, complementada por la compasión y la liberación ante el mismo que les otorga su fe en Cristo muerto y resucitado (Urbaniak, 2014). Debemos entender en este sentido el término «misticismo» como una forma de conciencia que supone una búsqueda y posterior encuentro con un fin último y desconocido de una realidad distinta de la que perciben nuestros sentidos (Craig, 2000).

El problema del sufrimiento para el Cristianismo tiene por tanto un componente místico que incluye el misterio y la interpretación sobre su origen que dificulta encontrar soluciones al mismo. Como ya señalara Gabriel Marcel (Marcel, 1949), un problema que puede ser explicado, cuando se logra dicha explicación, queda solucionado, pero el misterio resulta más complejo de interpretar y de atribuirle una solución científica y unívoca. Toda Teodicea trata de explicar la existencia de Dios, un Ser bondadoso y misericordioso y, a la vez, el sufrimiento de los hombres que en los albores del pensamiento cristiano se explica por la existencia del pecado original (Cardona Suárez, 2012).

Para los primeros cristianos, el dolor debía ser superado por una fe inquebrantable hasta el punto de que encontramos ejemplos, como el del apóstol Pablo en la Segunda Carta a los Corintios (1-7), en la que llega a pedir perdón por experimentar sufrimiento, padecimiento que solo es paliado por la capacidad de consolación de Dios, Ser en el que se encuentra dicho consuelo mediante la fe que lleva al ser humano a ser digno de sí y de Él.

Los cristianos, desde su mismo origen, han tratado de explicar tanto la belleza como el sufrimiento (Barton, 2014). El sufrimiento para los cristianos tiene un sentido moral y moralizante. No se trata de algo evitable, o que debamos intentar evitar —el mismo Jesús padeció en su persona sin eludirlo- pero piensan que se puede y se debe utilizar para renovar el carácter de las personas, como vía para el mejoramiento personal (Skeel, 2014). En las empresas, las situaciones de sufrimiento podrían tratar de aprovecharse del mismo modo para el desarrollo personal y el aprendizaje. Todos lo pasamos mal en el trabajo, como en otros órdenes de la vida, más tarde o más temprano. Saber aprovechar para bien esos momentos es lo que nos sugiere el cristianismo.

De la lectura de los grandes santos cristianos, se podría obtener la conclusión incluso de que el sufrimiento es una condición necesaria para llegar a ser un buen cristiano. Santa Teresa de Jesús afirmó: «Señor, déjame sufrir, o déjame morir». En otra ocasión, para describir una de sus experiencias místicas, escribe que «El sufrimiento fue tan grande que me hizo gemir y sin embargo sentí tanta dulzura que no pude desear librarme de él»(Santa Teresa de Jesús, 1987).

Algún autor ha escrito que esta forma de entender la vida en la que el sufrimiento se transforma en gozo tiene que ver con una concepción del mundo un tanto antihumanista (Berger, 1961) (Douglas, 1970), si bien otros han aclarado que dicha concepción no se refiere tanto, o tan sólo al dolor físico como a la autorrealización de la persona que se olvida de sí misma en su búsqueda de Dios (Urbaniak, 2014). No es considerado el sufrimiento como mero castigo físico, sino como sometimiento de las pasiones y control de los sentidos en aras a alcanzar un objetivo, un gozo mayor que el que nos ofrecen dichos sentidos (Baley, 1987).

No todas las concepciones de los místicos sobre el dolor son iguales sin embargo en la historia del Cristianismo. Para Eckhart de Hochheim tiene que ver con el 
desapego y el abandono de sí mismo, reflexión similar al budismo. Para Julián de Norwich tiene más que ver con la humanización de Jesús y el aspecto corporal de Dios (Davies, 2011). Todo converge sin embargo en lo que respecta al sufrimiento en la pasión de Cristo y la misión redentora del dolor (Urbaniak, 2014).

Podría considerarse que la esencia del pensamiento cristiano está contenido en labios de Jesús cuando pronuncia la frase «Si alguno de vosotros quiere ser mi seguidor, debe olvidarse de sí mismo, tomar su cruz y seguirme» (Marcos 8:34). Es la aceptación de la «cruz» personal de cada uno, la vía para lograr encontrar a Dios y hacerse uno con él, de forma que serán la fe y el amor los que logren superar el sufrimiento de los hombres (Urbaniak, 2014). No encaja esta afirmación de la aceptación del destino con la forma de entender las relaciones laborales en nuestros días, más tendentes a rebatir cuanto no satisface al sujeto, sin que por ello nos atrevamos a sugerir que uno u otro modo convenga más y/o mejor.

El pensamiento cristiano de los primeros tiempos tiene un gran parecido con el estoicismo que estaba entonces en vigor en el mundo greco-romano. Séneca fue un filósofo estoico cuyas ideas influyeron en gran medida en las bases de la doctrina cristiana. No existe documentación que respalde esta afirmación, pero sí sabemos que pensadores cristianos de la Edad Media como San Agustín, Tertuliano o San Jerónimo toman sus ideas y las utilizan de forma reiterada (Barja, 2005). La forma que tiene de concebir el dolor y que expresa en sus cartas anticipa la moral cristiana que hemos heredado pero que en realidad se remonta a la época helenística (Séneca, 2009) (Edwards, 1999).

Para algunos autores, el estoicismo es el pensamiento cristiano en potencia; no tiene su misma moral pero sí se aproxima mucho a ella. Son múltiples los parecidos entre el pensamiento religioso cristiano y el pensamiento religioso pagano de los estoicos. Los textos de Séneca tratan aspectos que son puramente cristianos y que desvelan la concepción cristiana del sufrimiento, como la importancia de la resignación, la aceptación de la adversidad, el sacrificio ante los impulsos de la carne o el desapego por los bienes materiales. La visión de una divinidad única de los estoicos, y por tanto de Séneca, se parece más al Cristianismo que el politeismo característico de la primera etapa del imperio romano. En un pasaje de las Cartas a Lucilo, Séneca escribe: «Dios se encuentra cerca de ti, contigo, en ti... En nuestro interior reside un espíritu sagrado al que no se oculta ninguna de nuestras obras, buenas o malas; y nos trata igual que lo tratamos.» (Séneca, 2009).

Séneca transforma el concepto de sufrimiento, meramente físico, imperante en Roma y le atribuye un valor de autoconocimiento y de progreso interior, algo útil en definitiva, influido tal vez por la presencia de la enfermedad en su propia existencia y su hipocrondria sobrevenida por tal motivo. Para él, no deberíamos estar preocupados por el dolor o el placer en sí mismos, sino por la interiorización de cuanto nos ocurre en la vida y que puede ser aprehendido para nuestro progreso (Edwards, 1999). Ya hemos referido a la importancia de aprovechar los momentos de sufrimiento, que se dan en las empresas como en cualquier otro ámbito, para mejorar nuestro destino y, en la medida de lo posible, evitar males futuros.

En referencia a Platón y Aristóteles, Séneca escribe que desde antiguo se conoce el sufrimiento del espítitu, pero es nuestro deber aprender y adaptar el método de curación a cada momento de la historia (Hadas, 1958). Esa fue su mayor aportación al pensamiento de los primeros cristianos y a su concepción del sufrimiento, 
muy influida por el suyo propio y que le llevó a incluir connotaciones como la resignación, la purificación, la compasión, o la misericordia en el mismo como componentes que le dan sentido y que serán pilares básicos para el pensamiento cristiano en sus primeros momentos de existencia.

\subsection{El sufrimiento para la filosofía islámica clásica}

El Islam también trata de responder, como toda religión, a la pregunta de las razones del sufrimiento en el mundo. El profeta Mahoma no fue ajeno al mismo ya desde niño, etapa en la que experimentó la muerte de sus padres y durante toda su vida por causa de la persecución y expulsión de la tribu a la que fue sometido debido a la incomprensión de su mensaje por sus coetáneos, allá por el siglo VII (Escobar Gómez, 2010).

No entiende sin embargo el Islam el sufrimiento como lo hace el Cristianismo en su misión redentora y capaz de aliviar la angustia por medio de la esperanza. Al menos en el Islam sunní que es el mayoritario en el mundo islámico, aunque sí haya alguna interpretación de tipo más parecido al Cristianismo en la forma de afrontar el sufrimiento por parte de la minoría sufí (Ayoub, 1978).

La forma de entender e interpretar el sufrimiento por el Islam puede ser considerada como fatalista, una manifestación de la necesaria paciencia ante el destino. Este sentido paciente enlaza en cierta medida con el estoicismo al que ya nos hemos referido más arriba. Incluso en algunos aspectos recuerda al budismo o al hinduismo, vistos también antes, pero la filosofía del Islam muestra un mayor pesimismo de fondo ante su actitud en esta vida (Ringgren, 1955).

Para el islam, las razones de que exista el sufrimiento y de que haya mal en el mundo, no corresponde responderlas a los seres humanos, sino que las sitúa bajo la sabiduría de Alá, que está muy por encima y que es inalcanzable para los seres humanos. Aunque El Corán deja algún resquicio a la racionalidad en expresiones como "Ciertamente, hay en ello signos para la gente que razona», en verdad para esta religión todo procede y es decidido en última instancia por Alá (Escobar Gómez, 2010).

Un asunto controvertido en nuestros días y que no es objeto de este trabajo es el carácter noble del martirio para los islamistas desde sus mismos orígenes y la importancia que otorgan al Día del Juicio que llega tras la muerte y en el que Dios decide sobre el destino. El sufrimiento en la Tierra está justificado por un bien muy superior que llega, a modo de premio, en una vida posterior y eterna (Kohlberg, 1980). No nos atrevemos a sugerir que haya algo aprovechable en esta forma de entender el sufrimiento para las empresas de nuestros días, si bien el conocimiento de esta forma de entender la vida debe ser igualmente comprendida.

Para los primeros filósofos del Islam, como al-Kiindi, al-Farabi, Avicena o Averroes, Alá ha creado el mejor de los mundos posibles y solo Él sabe por qué tenemos que sufrir y sólo Él sabe que el sufrimiento es necesario y bueno para tener una vida mejor en la eternidad. En cierto sentido, refieren al optimismo cosmológico ya expresado por Platón en el Timeo en el que afirma que el demiurgo creó todo tendiendo a lo mejor para los hombres (Platón, 1872). Dada la finitud de la capacidad del pensamiento y la comprensión humanas, debemos fiarnos de Dios como ordenador del mundo y aceptar el sufrimiento que en él existe y que 
padecemos. Lo imperfecto desde la estrecha visión del hombre es perfecto para Dios y su plan universal, siendo Él ya perfecto y sabedor de todo (Escobar Gómez, 2010). En cierto sentido, ocurre en nuestros días que los trabajadores, incluso los directivos de rango intermedio, fían su destino a los máximos mandatarios (los dioses de nuestros días). Son considerados como los regidores de un mundo global, y si la forma que tienen de entender la dirección de empresas hace sufrir a las personas, hay quien piensa que sus razones tendrán. Para algunos trabajadores, la forma actual de organizar las empresas, aunque produzca sufrimiento, lo convierte en un mal necesario para alcanzar el progreso.

Dios no niega el mal y el sufrimiento en el mundo, sino que lo considera como contribuyente al bien general sin que nada sobre en absoluto en dicho mundo. Así, aceptan en el Islam el sufrimiento como voluntad de Dios (Alá) y no como resultado de la causalidad natural o de los actos de los hombres que solo son, en su caso, vehículos necesarios para que el mal se produzca.

El considerado como primer filósofo musulmán, que vivió en el siglo IX, llamado Al-Kindi, escribió el libro titulado Arte de la consolación, en respuesta a la petición de un amigo a modo de consejos para paliar el sufrimiento. Lo primero que le dice Al-Kindi es que para contrarrestar el sufrimiento, hay que conocer sus causas y tener siempre presente que vivimos en un mundo material en el que existen y siempre existirán penas y sufrimientos (Ramón Guerrero \& Tornero Poveda, 1986). Esta reflexión dista de la expresada por el pensamiento del antigüo Oriente y que ya hemos recogido, para el que el dolor es inevitable como seres humanos que somos. Esto es así para distinguirlo del sufrimiento que proviene de la ignorancia del ser, de un modo de hacer que separa a los hombres de la senda que le provee el debido equilibrio. De este modo se evita el citado sufrimiento auque no se pueda eliminar el dolor consustancial al ser humano (Cavallé Cruz, 2010).

La pregunta que se hace el hombre por el sufrimiento parte de su propia experiencia, y no de reflexiones filosóficas respecto a la maldad o la naturaleza ontológica de lo humano. Tampoco respecto a la Justicia Divina que influirá, eso sí, en la respuesta, pero no en el planteamiento a priori de las razones para que exista el sufrimiento. Plantea después algo más parecido al pensamiento socrático y al oriental recién referido cuando afirma que el sufrimiento es una forma de ignorancia y que quien conozca el bien y la senda recta, evitará el sufrimiento. La Filosofía, el saber, es por tanto el camino que conduce a los seres humanos a la felicidad y los aleja del sufrimiento (Ramón Guerrero \& Tornero Poveda, 1986).

En este mundo, experimentamos sufrimiento cuando deseamos aquellas cosas que no podemos conseguir, de forma que el conocimiento de nuestros propios límites y la eliminación del mayor número posible de pasiones, nos aleja del sufrimiento. Esta reflexión que incorpora el Islam había sido ya expresada por el pensamiento clásico del que es un ejemplo la obra «Meditaciones» escrita por Marco Aurelio en la que afirma que "perseguir imposibles es propio de locos» (Marco Aurelio, 2008). Es común en los modelos de gestión de personas de nuestros días fomentar la lucha por el ascenso. Los trabajadores no son siempre conscientes de sus limitaciones ni existen sistemas de comunicación que informen sobre dichas carencias. Es habitual que un ascenso, lejos de hacer crecer al trabajador, le produzca sufrimiento.

Para el Islam clásico, tanto el sufrimiento como la alegría son pasajeros y un día terminan. Para ellos el sufrimiento no proviene necesariamente de la naturaleza 
humana, sino que también tiene que ver con el hábito, con la costumbre de cada individuo (Ramón Guerrero \& Tornero Poveda, 1986). Esta reflexión tiene influencia aristotélica en tanto en cuanto expresa que el hábito es algo así como el carácter que se forma a partir de la suma de hábitos e implica cierta voluntariedad para seguir el bien o desviarse del camino correcto. Esto produciría sufrimiento en el sujeto y le llevaría a buscar la felicidad en el alma a la que se somete en todo caso el cuerpo (Escobar Gómez, 2010).

Durante los siglos IX y X, se produce una intensa actividad intelectual que se ha denominado «el renacimiento en el Islam». De entre los múltiples pensadores de esta época descata, por lo que hace al objetivo de este trabajo de investigación, Abû Bakr al-Râzî. El citado autor, dedica gran parte de su obra al estudio del sufrimiento y su relación con el placer (Amad Al-Razi, 2004). Para este pensador, el placer no debe ser rechazado salvo cuando en sí mismo produce sufrimiento, una forma de pensar que recuerda más a la postura epicúrea que a la estoica. Lo más importante de sus trabajos es su afirmación de que el sufrimiento debe ser evitado en la medida de lo posible y en todo caso por carecer de cualquier connotación positiva. Sin embargo es consciente de que ha de existir porque así es la esencia de los seres humanos, y afirma que de existir, debe procurársele un fin loable y darle el sentido necesario para convertirlo en algo digno (Amad Al-Razi, 2004).

Transcurridos los primeros momentos, el Islam clásico se caracteriza por una doble interpretación del sufrimiento. Una primera corriente representada por AlFarabi, Avicena y Averroes sobre todo, parte de una concepción metafísica del sufrimiento por la que el padecimiento encuentra su sentido como parte necesaria del orden universal y para la que el alcance de los seres humanos respecto al mismo es irracional y parcial. Otra corriente, formada por pensadores más cercanos al humanismo y representada por Al-Marri o Ibn Hazm, trata de explicar el sufrimiento como parte insoslayable de la naturaleza humana y más que justificarlo, lo trata de explicar solo cuando obra un fin bueno o, si no, inevitable (Escobar Gómez, 2010).

\section{CONCLusiones}

Las aportaciones que hemos ofrecido hasta aquí de la Filosofía han sido meramente descriptivas. Sin embargo, más allá aún, debemos considerar la posibilidad de incluir en este trabajo una serie de conclusiones propositivas o de carácter práctico para la acción. Esto, completará el objeto del presente trabajo que, como ya hemos señalado, busca contribuir a la mejora de los modelos de gestión de personas que existen en la actualidad. Las conclusiones que presentamos tienen por tanto un sentido, si no prescriptivo, cuanto menos propositivo.

1.- Para el pensamiento del Lejano Oriente, la fuente principal del sufrimiento es la ignorancia de la realidad. Cuando se posee un verdadero conocimiento de lo que ocurre, los resultados se aprecian de forma significativa (Cavallé Cruz, 2010). Deben analizarse los sistemas de conocimiento de las personas en las organizaciones. Serían para ello necesarias más y mejores herramientas, pero también más equipos humanos y una mayor y mejor dedicación del tiempo al sufrimiento de las personas. 
2.- Sugerimos comprobar asimismo la existencia de sistemas para que las personas avancen en su autoconocimiento. Cada empleado ha de poder saber su valía a juicio de la organización, y las posibilidades de crecimiento que le otorga. En Antiguo Oriente se afirma que el autoconocimiento es la mejor vía para conseguir que cese el sufrimiento en las personas.

3.- Para la Antigüedad Clásica, el conocimiento, la sabiduría en sí misma, minora el sufrimiento en las personas. La combinación de intelecto y ciencia para alcanzar el conocimiento perfecto hace a los hombres mejores y les procura mayor felicidad (Aristóteles, 2010). Los empleados realizan con demasiada frecuencia, tareas que no saben para qué servirán, ni si serán de alguna utilidad. Carecen del conocimiento del sentido de su trabajo y eso produce alienación y sufrimiento.

4.- Los modelos de gestión de personas deben reconocer la existencia del sufrimiento y tratar de aceptarlo como primer paso para, después, analizarlo, afrontarlo y prevenirlo. Así lo hizo el pensamiento cristiano, que además incorpora los conceptos de compasión y de necesaria liberación ante el mismo (Urbaniak, 2014). Sugerimos también incluir la noción de compasión en los modelos de gestión de personas, concepto inexistente en el día a día de nuestras empresas. Ésta se haría realidad estando atentos y ocupados de cada realidad individual en aras a darle solución en la medida de lo posible.

Nos preguntamos al inicio si el pensamiento filosófico podría ayudar a establecer esos métodos de escucha y de ayuda a los empleados, y concluimos que, en efecto, la interpretación del sufrimiento a lo largo de la historia de la Filosofía, puede ayudar en el empeño. Proponemos valorar las posibles acciones de los gestores de personas con la interpretación del sufrimiento y las propuestas de solución en las distintas etapas del pensamiento filosófico.

Sugerimos, en todo caso, la incorporación en los modelos de gestión de personas de políticas que aborden de forma directa, individualizada, anónima, y voluntaria, el problema del sufrimiento en los trabajadores. Es una tarea posible, pero más aún, se trata de una misión necesaria a la que puede y debe contribuir el pensamiento filosófico.

\section{BiBLIOGRAFÍA}

Amad Al-Razi, I. B. (2004). La conducta virtuosa del filósofo Al-Razi. Madrid, España: Trotta. Aristóteles. (2010). Ética a Nicómaco. Madrid: Gredos.

Aristóteles. (1998). Metafísica. Madrid: Gredos.

Ayoub, M. (1978). Redemptive Suffering in Islam: A Study of the Devotional Aspects of Ashura in Twelver Shiísm. Londres: Gruyter Mouton.

Bailey, R. (1987). Thomas Merton on Mysticism. Nueva York: Doubleday.

Barton, S. (22 de Noviembre de 2014). In Praise of Gentle Apologias. Wall Street Journal, pág. 12.

Berger, P. (1961). The Precarious Vision. A Sociologist Looks at Social Fictions and Christian Faith. Nueva York: Doubleday \& Company.

Black, H., \& Rubinstein, R. (2004). Themes of suffering in later life. Journals of Gerontology, $59 B, 17$ ss.

Boeri, M. (2004). Los estoicos antiguos. Sobre la virtud y la felicidad. Santiago de Chile: Editorial Universitaria. 
Cantillo, C. (2010). Sonreír a Través de las Lágrimas; Arte y Dolor. En M. González García, Filosofía y Dolor (págs. 217-231). Madrid: Tecnos.

Cardona Suarez, L. F. (diciembre de 2012). La transformación leibnizieana de la doctrina del pecacatum originale. Filosofía, 405-412.

Cassell, E. (Marzo de 1982). The Nature of Suffering and the Goals of Medicine. The New England Journal of Medicine, 639-645.

Cavallé Cruz, M. (2010). El Vedanta Advaita ante el Sufrimiento. En M. González García, Filosofía y Dolor (págs. 19-61). Madrid: Tecnos.

Copleston, F. (1901). Historia de la Filosofía. Barcelona: Ariel.

Craig, E. (2000). Concise Routledge Encyclopedia of Philosophy. Londres, Reino Unido: Routledge.

Davies, O. (2011). Meister Eckhart: Mystical Theologian. Journal of Religion and Society.

Denault, S., Lussier, V., Mongeau, S., Paille, P., et al., e. (2004). The Nature of Suffering and Its Relief in tthe Terminally III. 20, 7-12.

Douglas, M. (1970). Natural Symbols. Reino Unido: Barrie \& Rockliff.

Edwards, C. (1999). The suffering body: philosophy and pain in Seneca's Letters. En J. Porter, Constructions of the body in Classical Antiquity (págs. 252-268). Michigan: University of Bristol.

Escobar Gómez, S. (2010). El concepto del sufrimiento en la filosofía islámica clásica. En M. González García, Filosofía y Dolor (pág. 502). Marid: Tecnos.

González García, M. (2010). Filosofía y Dolor. Madrid: Tecnos.

Hadas, M. (1958). The Stoic Philosophy of Seneca. Londres, Reino Unido: Norton \& Company.

Han, B.-C. (2014). Psicopolítica. Neoliberalismo y nuevas técnicas de poder. (Herder, Ed.) Barcelona. Barcelona: Pensamiento Herder.

Hirschberger, J. (1968). Historia de la Filosofía, Tomo I. Barcelona: Herder.

Homero. (2007). Odisea. Ediciones SM.

Santa Teresa de Jesús (1987). The Life of Saint Teresa of Avila by Herself. (Penguin, Ed.)

Kohlberg, E. (1980). Reviewed Work: Redemptive Sufffering in Islam: A Study of the Devotional Aspects of Ashura in Twelver Shiísm. (C. U. Press, Ed.)

Levinas, E. (1991). Entre nous (Essais sur le penser-á-l'autre. Détermination philosophique de l'Idee de culture. París: Grasset.

López Sáenz, M. d. (2010). Herbert Marcuse (1878-1979): Trabajo y Dolor como consecuencias de la represión. En M. González García, Filosofía y Dolor (págs. 439-454). Madrid: Tecnos.

Marcel, G. (1949). Being and Having. (T. U. Press, Ed.) Glasgow. Escocia: Dacre Press Westminster.

Marco Aurelio, (2008). Meditaciones. Madrid: RBA Libros.

Marías, J. (1941). Historia de la Filosofía. Madrid: Manuales de la Revista de Occidente.

Merlo, V. (1994). Experiencia Yóguica y Antropología Filosófica. Fundación Centro Sri Aurobindo.

Montoya Juarez, R., Schimidt Río-Valle, J., \& Prados Peña, D. (2006). En busca de una definición transcultural de sufrimiento; una revisión bibliográfica. Cultua de los Cuidados, 20, 117-120.

Morera de Guijarro, J. I. (2010). Sabiduría y Aflicción en la Grecia Arcaica (Aquiles, Pandora, Orfeo). En M. González García, Filosofía y Dolor (pág. 502). Madrid: Tecnos.

Morse, J. (2000). Researching illness and injury: Mithodological Considerations. Qualitatlive Health Research, 10 (4), 538-546.

Nietzsche, F. (1886). El nacimiento de la tragedia. Biblioteca Nueva.

Nisargadatta, M. (2000). Yo soy eso. Málaga: Sirio.

Peirce, C. (1898). Philosophy and the Conduct of Life., (págs. 616-649).

Platón. (1872). Timeo. En P. De Azcárate, \& M. y. Navarro (Ed.), Platón, Obras completas (Vol. VI, pág. 293). Madrid, España.

Ramón Guerrero, R., \& Tornero Poveda, E. (1986). Obras filosóficas de Al-Kindi. Madrid: Coloquio. 
Ringgren, H. (1955). Studies in Arabian Fatalism (Vol. 1). Upsala Wiesbaden, Wiesbaden: Upsala Universitets Arsskrift.

Sánchez Meca, D. (2010). Com-Padecer Sim-Patizar: Hacia una filosofía de la Hospitalidad. En M. González García, Filosofía y Dolor (págs. 471-489). Madrid: Tecnos.

Santa Biblia (2003). II Carta de San Pablo a los Corintios 1-7. España: Casa Promesa.

Santa Teresa de Jesús (1987). The Life of Saint Teresa of Avila by Herself. (Penguin, Ed.)

Seligmann-Silva, E. (2014). Trabajo y Desgaste Mental. El derecho a ser dueño de sí mismo. Sao Paulo: Octaedro.

Séneca. (2009). Cartas a Lucilio. Carta 73. Editorial Juventud.

Shankaracharya. (1965). Brahma Sutra Bhasya. Advaita Ashrama.

Skeel, D. (2014). True Paradox: How Christianity Makes Sense of Our Complex World. IVP Books.

Urbaniak, J. (2014). Suffering in the mystical traditions of Buddihism and Chirstianity. Theological Studies, 70 (1), 1-10.

Vigne, J. (1995). No-dualidad y Mística Cristiana: Vedanta y Hesicasmo. Questions, 99-100, 1-49.

Zhuangzi. (1972). Chuang-zu. Barcelona: Kairos.

Universidad Pontificia Comillas, Madrid

egismera@comillas.edu

jlfernandez@comillas.edu

jlabrador@comillas.edu

[Artículo aprobado para publicación en enero de 2019]
EDUARdo Gismera TiERNO

José LUIS FERNÁNDEZ FERNÁNDEZ

Jesús Labrador FERNÁNDEZ 